\title{
Photochromic silicone polymers based on 1,2-dihetarylethenes
}

\author{
Natalia G. Shimkina, ${ }^{\text {a* }}$ Mikhail M. Krayushkin, ${ }^{\text {a }}$ Valery A. Barachevsky, ${ }^{\text {b }}$ Aleksander A. \\ Dunaev, ${ }^{b}$ Boris A. Izmailov, ${ }^{\text {c Valery A. Vasnev, }}{ }^{c}$ and Mukhamed L. Keshtov ${ }^{c}$ \\ ${ }^{a}$ N. D. Zelinsky Institute of Organic Chemistry, Russian Academy of Sciences Leninsky Pros. 47, \\ 119991 Moscow, Russian Federation \\ ${ }^{b}$ Photochemistry Center, Russian Academy of Sciences ul. Novatorov 7a, 119421 Moscow, \\ Russian Federation \\ ${ }^{c}$ A.N. Nesmeyanov Institute of Organoelement Compounds, Russian Academy of Sciences \\ Ul. Vavilova 28, Moscow 19991, Russian Federation \\ E-mail:nagesm@mail.ru
}

\section{Dedicated to Professor I. P. Beletskaya on the occasion of her jubilee}

\begin{abstract}
Silicone polymer coatings (PC) containing new photochromic dihetarylethene moieties (DEA) were prepared. The efficiency of photochromic transformations in the coatings has been studied. The polyisononylsilazane coating was found to possess the best photochromic properties with an achievable optical density of 0.21 .
\end{abstract}

Keywords: Photochromes, dihetarylethenes, silicone polymers, dithienylmaleimides

\section{Introduction}

One of the most actual problems in the field of informational nanotechnology is the development of photochromic recording media for three-dimensional optical memory with high information capacity. ${ }^{1-3}$ Usually these light-sensitive materials are developed by employment of thermally irreversible photochromic compounds, particularly 1,2-diarylethenes (DAE), in polymer binders. Unfortunately, the information capacity (resolution) of these recording media is limited by diffusion and low content (up to 5 mass \%) of photochromic compounds in a polymer matrix.

The present paper reports on the synthesis and on the spectral-kinetic study of photochromic three-dimensional silicone polymers (coatings) based on 1,2-dihetarylethenes with N-hydroxyethyl and $\mathrm{N}$-allyl groups, polysiloxanes and polysilazanes. The polymers prepared contain photochromic moieties linked to the polymer chain by covalent bonds that allow achieving high concentration of photochromic units (up to $40 \%$ ). 


\section{Results and Discussion}

For the first time, DAE moieties were introduced into the structures of silicone polymers, namely polysiloxanes and polysilazanes, which are known to form transparent polymer coatings (PC) on a silicate glass under the action of moist air. The structures of the starting silicones 1-3 are presented in Figure 1.

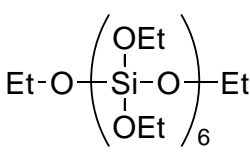

1

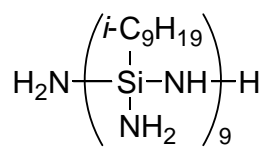

2

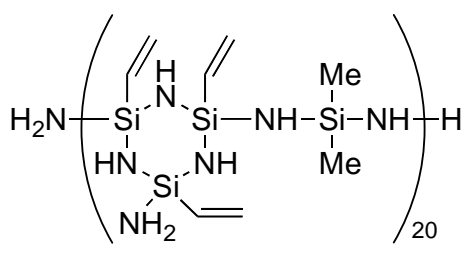

3

Figure 1. Structures of the starting silicones: ethyl silicate 40 (1), polyisononylsilazane (2), polyvinyldimethylsilazane (3).

The DAEs that becomes attached to polymers contains specific binding groups: hydroxyl for silicones 1, 2 and allyl for silazane 3. As the basis of the photochromic polymers we chose DAEs containing two benzothiophene groups connected by a maleimide bridge; diarylmaleimide derivatives are well known for their photochromic properties.

The reaction of 1,2-bis(2-methylbenzo[b]thiophen-3-yl)maleic anhydride $\mathbf{4}$ with ethanolamine and allylamine provided the corresponding maleimides 5a,b containing the Nhydroxyethyl and $\mathrm{N}$-allyl group, respectively (Scheme 1).

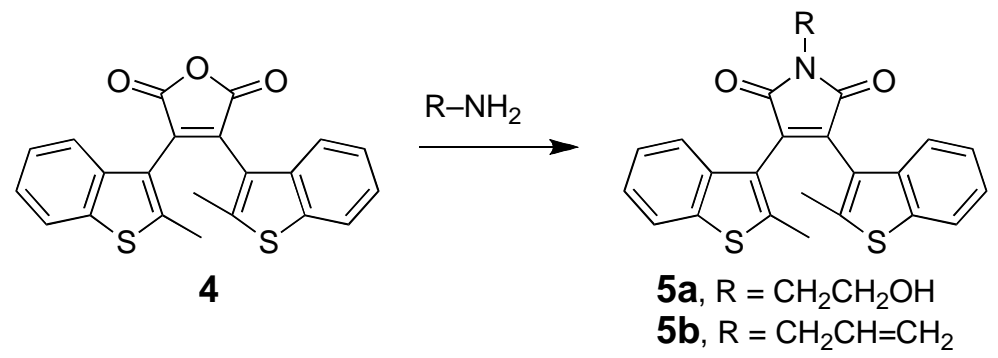

\section{Scheme 1}

The photochromic polymers $\mathbf{6}$ and 7 were prepared by the reaction of silicones $\mathbf{1}$ and $\mathbf{2}$ with DAE 5a; polymer 8 resulted from silazane 3 reacting with $\mathbf{5 b}$. Condensation of silicones $\mathbf{1}$ and $\mathbf{2}$ with the hydroxyl group of DAE 5a led to the displacement of ethanol and ammonia, respectively (Scheme 2). The vinyl groups of silazane $\mathbf{3}$ reacting with the allyl group of $\mathbf{5 b}$ furnished the co-polymer 8 (Scheme 2). 


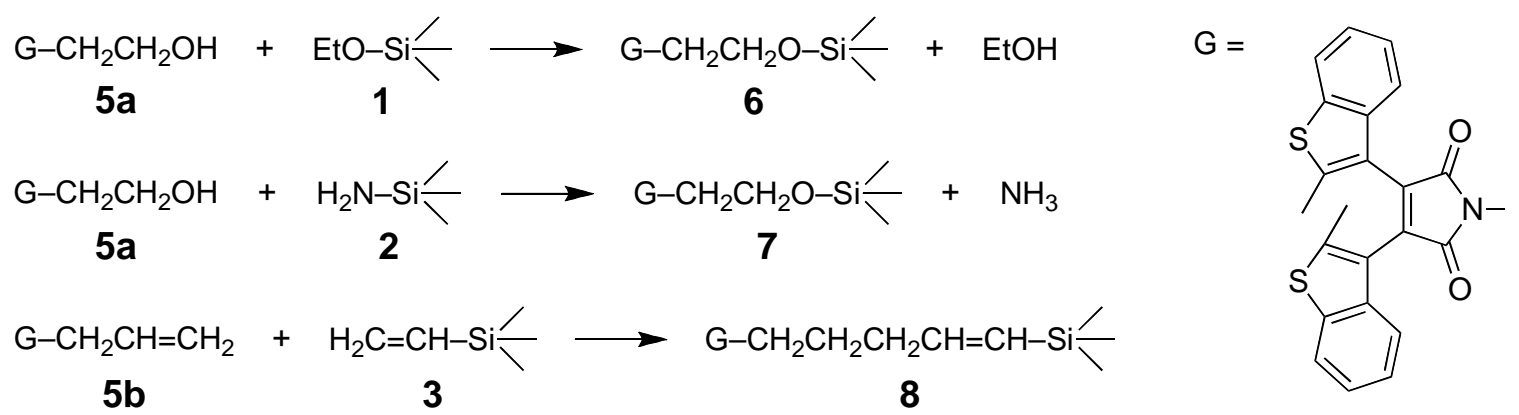

\section{Scheme 2}

The silicates 6-8 react further with moist air and with the hydroxyl groups of silicate glass resulting in the formation of three-dimensional polymer silicone coatings PC-6-8 (Figure 2).

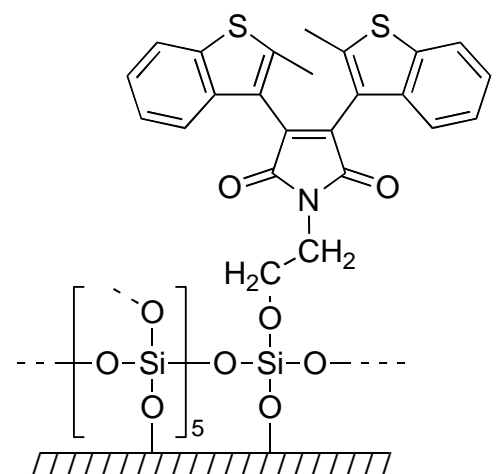

PC-6

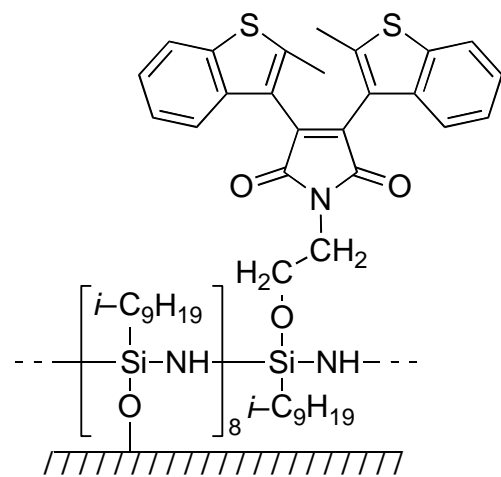

PC-7<smiles>Cc1sc2ccccc2c1C1=C(c2c(C)sc3ccccc23)C(=O)NC1=O</smiles>

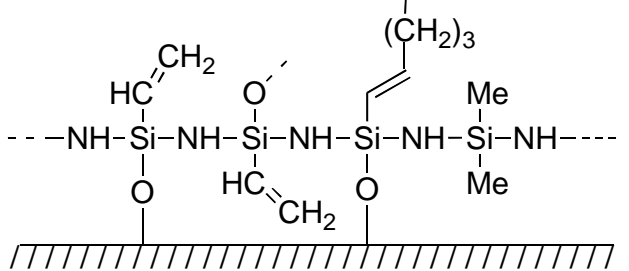

PC-8

Figure 2. Structures of the polymer coatings PC-6-8 on silicate glass.

On exposure to light, diarylethenes $\mathbf{5 a}, \mathbf{b}$ undergo reversible phototransformation caused by valence isomerization between the open and cyclic forms $\mathbf{A}$ and $\mathbf{B}$, respectively ${ }^{1,3}$ (Scheme 3).

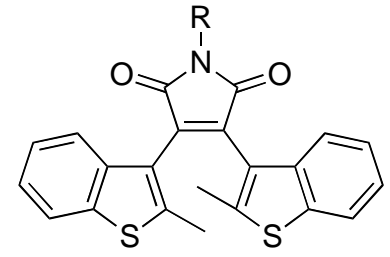

A $(5 a, b)$
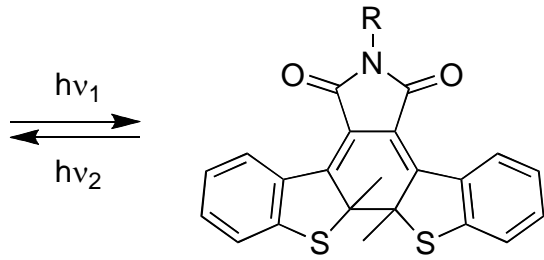

B

\section{Scheme 3}

Spectral kinetic characteristics of solutions of DAE $\mathbf{5 a}, \mathbf{b}$ in DMF were preliminarily measured. Figure 3 shows the absorption spectra of the open and ring forms of compound $\mathbf{5 a}$. 


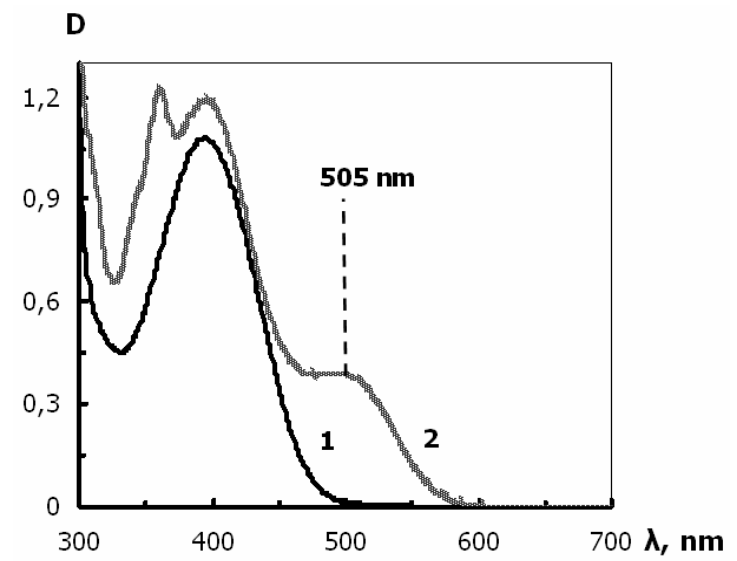

Figure 3. Absorption spectra of a solution of compound 5a in DMF (c $=2.5 \cdot 10^{-3} \mathrm{M}$ ) before (1) and after (2) UV irradiation at $\lambda=380 \mathrm{~nm}$.

Similar spectral characteristics for the open and cyclic forms were obtained for compound 5b. The kinetic characteristics of $\mathbf{5 a}$ and $\mathbf{5 b}$ were identical (Figure 4).

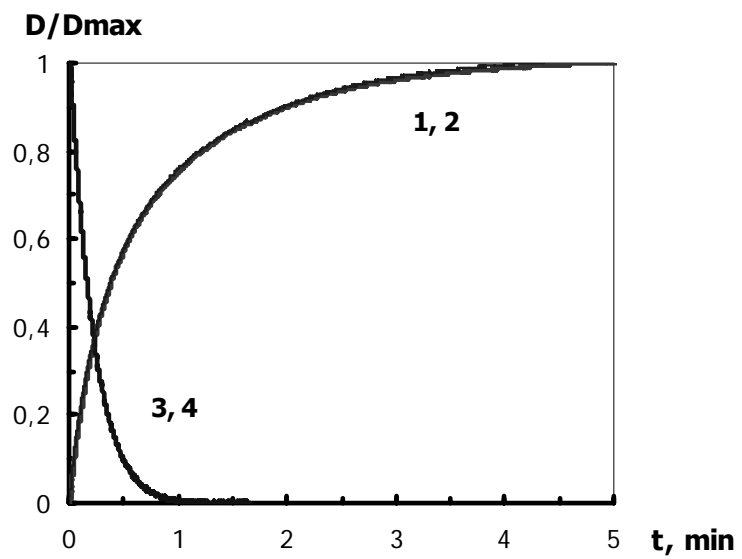

Figure 4. Kinetic curves for photoinduced coloration $(1,2)$ and bleaching $(3,4)$ of compounds $\mathbf{5 a}(1,3)$ and $\mathbf{5 b}(2,4)$ in DMF, respectively. Recorded at the absorption maximum of the cyclic forms $(505 \mathrm{~nm})$.

Exposure of DMF solutions of these compounds to unfiltered xenon light showed a very high stability against photodestruction indicating a high cyclic recurrence of reversible phototransformations of these compounds.

In the process of polymer coatings preparation, attempts were made to include a maximum quantity of DAE to the silicone system. However, above a certain quantity of DAE there was a stratifying of the reaction mixture. In Table 1 the maximum achievable values of DAE quantity in polymers are specified. 
Table 1. Spectral kinetic characteristics of photochromic polymer coatings (PC) obtained from DAE and silicones

\begin{tabular}{cccc}
\hline Samples & \multicolumn{3}{c}{ Spectral kinetic characteristics* } \\
\cline { 2 - 4 } (molar ratio of polymer unit : DAE) & $\lambda^{\mathrm{A}}{ }_{\max }, \mathrm{nm}^{*} \mathrm{D}^{\mathrm{A}}{ }_{\max }$ & $\lambda^{\mathrm{B}}{ }_{\max }, \mathrm{nm} / \Delta \mathrm{D}^{\mathrm{B}}{ }_{\max }$ & $\mathrm{k}_{\mathrm{A}-\mathrm{B}} / \mathrm{k}_{\mathrm{B}-\mathrm{A}}$ \\
\hline $\mathbf{5 a}(\mathbf{5 b})$ in DMF & $390 / 1.0$ & $505 / 0.35$ & 0.80 \\
PC-6 $(\mathbf{1}+\mathbf{5 a}, 6: 1)$ & $409 / 1.0$ & $520 / 0.03$ & 0.77 \\
PC-7 $(\mathbf{2}+\mathbf{5 a}, 36: 1)$ & $409 / 1.2$ & $520 / 0.21$ & 2.15 \\
PC-8 $(\mathbf{3}+\mathbf{5 b}, 2.0: 1)$ & $409 / 1.0$ & $520 / 0.15$ & 0.69 \\
PC-8 $(\mathbf{3}+\mathbf{5 b}, 2.5: 1)$ & $409 / 1.0$ & $520 / 0.09$ & 0.39 \\
\hline
\end{tabular}

$* \lambda_{\text {max }}^{\mathrm{A}} / \mathrm{D}^{\mathrm{A}}$ max is the position of the absorption maximum/optical density at the maximum of the open isomer $\mathbf{A}$ (before irradiation); $\lambda^{\mathrm{B}}{ }_{\max } / \Delta \mathrm{D}^{\mathrm{B}}{ }_{\text {max }}$ is the position of the absorption maximum/ photoinduced change in optical density in the long-wavelength absorption maximum of the cyclic isomer $\mathbf{B}$ at the photostationary state during $\mathrm{UV}$ irradiation; $\mathrm{k}_{\mathrm{A}-\mathrm{B}}, \mathrm{k}_{\mathrm{B}-\mathrm{A}}$ are rate constants of the photoinduced coloration $\left(\mathrm{I}_{\mathrm{oUV}}=12 \mathrm{~mW} / \mathrm{cm}^{2}\right)$ and bleaching $\left(\mathrm{I}_{\mathrm{oVIS}}=152 \mathrm{~mW} / \mathrm{cm}^{2}\right)$ processes.

Introduction of photochromic compounds into a polymer chain cause bathochromic shifts of the absorption maxima of both open and cyclic forms of dihetarylethenes as compared to solutions. Photochromic PC-6, based on ethyl silicate 40 (1), was found to be the least lightsensitive. Light sensitivity determined by the value of photoinduced change in optical density at the absorption maximum of the cyclic isomer $\mathbf{B}$ for polyvinyldimethylsilazane (3)-based coatings PC-8 increases with an increase in the content of dihetarylethene fragments in the polymer chain. But most important is the nature of polymer matrix. PC-7 obtained from polyisononylsilazane proved to be the most light-sensitive, though its coloration is not as effective as the coloration of solutions (Table 1). The observed photoinduced spectral changes are presented in Figure 5.

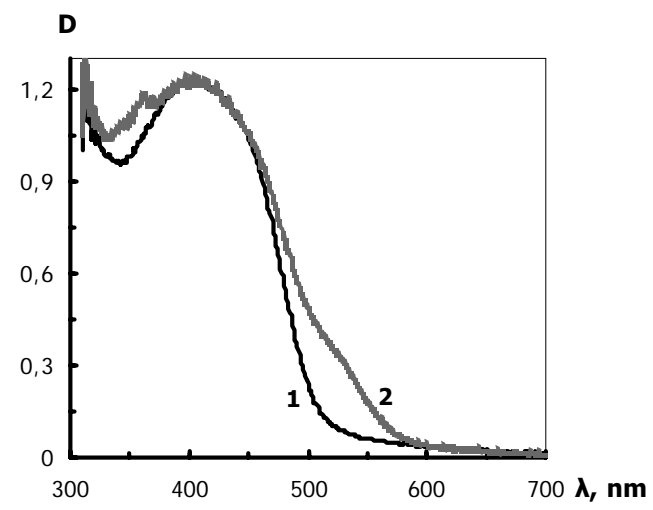

Figure 5. Absorption spectra of the photochromic silicone coating PC-7 based on polyisononylsilazane 2 and DAE 5a before (1) and after (2) UV radiation at $\lambda=380 \mathrm{~nm}$. 
The analysis of the values of photoinduced optical density at the absorption maximum for the cyclic form in the visible region (Table 1) indicates that the photocoloration efficiency of photochromic compounds increases in the following sequence of polymer matrices: ethyl silicate 40 (1) < polyvinylsilazane (3) << polyisononylsilazane (2).

Unfortunately, quantum yields were not measured; therefore, the efficiency of photocoloration was roughly established from the analysis of the ratio of photocoloration and photobleaching rate constants $\mathrm{k}_{\mathrm{A}-\mathrm{B}}$ and $\mathrm{k}_{\mathrm{B}-\mathrm{A}}$ under comparable photoexcitation conditions. It follows that in the case of polyvinyldimethylsilazane coatings PC-8, the efficiency of photocoloration diminishes, while it markedly grows in the case of polyisononylsilazane-based PC-7 compared to that of solutions of unsubstituted dihetarylethene, obviously due to the effect of the structure of the polymer matrix on the conformation of the dihetarylethene open form.

\section{Experimental Section}

General Procedures. 1,2-Bis(2-methylbenzo[b]thiophen-3-yl)maleic anhydride 4 was prepared by reported procedures. ${ }^{4,5}$ Ethyl silicate 40 (1) with $99.5 \%$ major component was used as received (Pentasilicone). Polyisononylsilazane $\mathbf{2}$ was obtained by ammonolysis of isononylchlorosilane by a published procedure. ${ }^{6}$ Polyvinyldimethylsilazane $\mathbf{3}$ was synthesized by co-ammonolysis of trichlorovinylsilane $(3 \mathrm{~mol})$ with dichlorodimethylsilane $(1 \mathrm{~mol})$ by a known procedure. ${ }^{6}$ Commercial chemicals (Acros) were used for the synthesis of DAEs.

Melting points were measured on a Boetius hot stage. ${ }^{1} \mathrm{H}$ NMR spectra were recorded on a Bruker AC-300 spectrometer $(300 \mathrm{MHz})$ in $\mathrm{CDCl}_{3}$. Mass spectra were recorded on a Kratos instrument with direct sample injection into the ion source (ionization energy $70 \mathrm{eV}$, control voltage 1.75 $\mathrm{kV})$.

\section{DAE 5. General procedure}

A solution of 1,2-bis(2-methylbenzo[b]thiophen-3-yl)maleic anhydride 4 (0.5 g, $1.28 \mathrm{mmol})$ and the corresponding amine $(1.41 \mathrm{mmol})$ in ethanol $(30 \mathrm{~mL})$ was placed in a round-bottom flask equipped with a reflux condenser; $p$-toluenesulfonic acid (25 $\mathrm{mg}, 0.13 \mathrm{mmol}$ ) was added, and the mixture was refluxed for $1 \mathrm{~h}$. The reaction mixture was poured in water and extracted with chloroform. The extract was washed with water, dried with magnesium sulfate, and concentrated. The residue was purified by flash chromatography (silica gel; petroleum ether/ethyl acetate 3:1).

\section{1-(2-Hydroxyethyl)-3,4-bis(2-methylbenzo[b]thiophen-3-yl)-1H-pyrrole-2,5-dione}

(5a). Orange powder $(0.50 \mathrm{~g}, 90 \%)$; mp $195-196{ }^{\circ} \mathrm{C} .{ }^{1} \mathrm{H}$ NMR $\left(300 \mathrm{MHz}, \mathrm{CDCl}_{3}\right): \delta 2.05(3 \mathrm{H}, \mathrm{s}$, $\left.\mathrm{CH}_{3}\right), 2.30\left(3 \mathrm{H}, \mathrm{s}, \mathrm{CH}_{3}\right), 3.98\left(4 \mathrm{H}, \mathrm{s}, 2 \mathrm{CH}_{2}\right), 7.08\left(1 \mathrm{H}, \mathrm{t}, J=7.3 \mathrm{~Hz}, \mathrm{H}_{\mathrm{Ar}}\right), 7.17-7.32(4 \mathrm{H}, \mathrm{m}$, $\left.\mathrm{H}_{\mathrm{Ar}}\right), 7.48\left(1 \mathrm{H}, \mathrm{d}, J=7.4 \mathrm{~Hz}, \mathrm{H}_{\mathrm{Ar}}\right), 7.63-7.72\left(2 \mathrm{H}, \mathrm{m}, \mathrm{H}_{\mathrm{Ar}}\right) . \mathrm{MS}: m / z(\%) 433\left(100, \mathrm{M}^{+}\right)$. Anal. calcd. for $\mathrm{C}_{25} \mathrm{H}_{19} \mathrm{NO}_{2} \mathrm{~S}_{2}$ : C, 66.49; H, 4.42; N, 3.23; S, 14.79. Found: C, 66.56; H, 4.40; N, 3.30; $\mathrm{S}, 14.87$. 
1-(Allyl)-3,4-bis(2-methylbenzo[b]thiophen-3-yl)-1H-pyrrole-2,5-dione (5b). Orange powder (0.49 g, 89\%); mp 148-150 ${ }^{\circ} \mathrm{C} .{ }^{1} \mathrm{H}$ NMR (300 MHz, $\left.\mathrm{CDCl}_{3}\right): \delta 2.08\left(3 \mathrm{H}, \mathrm{s}, \mathrm{CH}_{3}\right), 2.30(3 \mathrm{H}, \mathrm{s}$, $\left.\mathrm{CH}_{3}\right), 4.39\left(2 \mathrm{H}, \mathrm{d}, J=5.6 \mathrm{~Hz}, \mathrm{CH}_{2}\right), 5.32\left(2 \mathrm{H}, \mathrm{t}, J=13.7 \mathrm{~Hz}, \mathrm{CH}_{2}\right), 6.00(1 \mathrm{H}, \mathrm{m}, \mathrm{CH}), 7.08(1 \mathrm{H}$, $\left.\mathrm{t}, J=7.4 \mathrm{~Hz}, \mathrm{H}_{\mathrm{Ar}}\right), 7.17-7.35\left(4 \mathrm{H}, \mathrm{m}, \mathrm{H}_{\mathrm{Ar}}\right), 7.45\left(1 \mathrm{H}, \mathrm{d}, J=7.4 \mathrm{~Hz}, \mathrm{H}_{\mathrm{Ar}}\right), 7.65-7.75(2 \mathrm{H}, \mathrm{m}$, $\left.\mathrm{H}_{\mathrm{Ar}}\right)$. MS: $\mathrm{m} / \mathrm{z}(\%) 429\left(94, \mathrm{M}^{+}\right)$. Anal. calcd. for $\mathrm{C}_{25} \mathrm{H}_{19} \mathrm{NO}_{2} \mathrm{~S}_{2}$ : C 69.90; $\mathrm{H} 4.46 ; \mathrm{N}$ 3.26; $\mathrm{S}$ 14.93. Found: C 69.76; H 4.55; N 3.30; S 14.70.

Polymeric photochromic coatings (PC) based on DAE were produced by curing of silicone/DAE mixtures induced by moist air at room temperature. The preparation of PC-8 from polyvinyldimethylsilazane $\mathbf{3}$ and DAE $\mathbf{5 b}$ serves as a typical example.

\section{Photochromic polymer coating PC-8. Typical procedure}

A solution of polyvinyldimethylsilazane $3\left(0.1327 \mathrm{~g}, 4.4 \cdot 10^{-4}\right.$ base mol) in toluene/butyl acetate $(1: 1 \mathrm{v} / \mathrm{v}, 2 \mathrm{~mL})$ was mixed in a beaker at room temperature with a solution of $\mathbf{5 b}(0.0946 \mathrm{~g}$, $\left.2.2 \cdot 10^{-4} \mathrm{~mol}\right)$ in butyl acetate $(0.1 \mathrm{~mL})$. The resulting solution was applied to a silicate glass and left at room temperature for 2 days until the solvent has evaporated and the polysilazane coating was formed. The coating was heated to $70{ }^{\circ} \mathrm{C}$ for $30 \mathrm{~min}$, kept for $1 \mathrm{~h}$; then the temperature was raised to $150{ }^{\circ} \mathrm{C}$ for $1 \mathrm{~h}$, and kept at this temperature for $3 \mathrm{~h}$ until a transparent strong polymer silicone coating had formed.

The photochromic polymer layer was about $50 \mu \mathrm{m}$ thick. In order to obtain comparable spectral kinetic data, the thickness of film samples was reduced mechanically by polishing to such an extent that the absorbance in the absorption maximum of the open form of the photochromic film was about $\mathrm{D}=1.0$. The thickness of these films was $5 \mu \mathrm{m}$ as measured by an interferometer. To eliminate light scattering, a thin layer of a transparent silicone sealant or a transparent polyvinyl alcohol layer was applied to the film surface.

The absorption spectra in the 190-800 $\mathrm{nm}$ range and the kinetic curves for phototransformations were measured using a Varian Cary 50 Bio spectrophotometer. The absorption spectra and the kinetic curves of a DMF solution of DAE were recorded in a $1 \mathrm{~mm}$ thick cell.

An L8253 xenon lamp included in a LC-4 radiation unit with a fiber optic sensor (Hamamatsu) was used as the excitation radiation source. The distance from the optical waveguide to the sample was $5 \mathrm{~cm}$.

Photocoloration was induced by UV light at about $380 \mathrm{~nm}$ isolated from the radiation of the lamp by BS-8, SZS-23, and YFS-5 glass filters (Lomo) $\left(12 \mathrm{~mW} / \mathrm{cm}^{2}\right)$. Photobleaching was attained by exposure to visible light at more than $500 \mathrm{~nm}$ using a $\mathrm{ZhS}-18$ light filter $\left(152 \mathrm{~mW} / \mathrm{cm}^{2}\right)$. Where it was necessary to determine the sample stability under continuous radiation, no filters were used. The radiation power of the lamp was maximum in all modes.

\section{Conclusions}

All silicone polymer coatings containing photochromic DAE moieties exhibit photochromic 
properties. The efficiency of photochromic transformations in the coatings decreases as compared to that of solutions of the starting DAE and depends on the structure of the polymer matrix and the ratio of the photochromic moiety in the polymer.

\section{Acknowledgements}

This work was supported by the Russian Foundation for Basic Research (Project 07-03-00729).

\section{References}

1. Irie, M. Chem. Rev. 2000, 100, 1685.

2. Krayushkin, M. M. Chem. Heterocycl. Compd. (Engl. Transl.) 2001, 37, 15.

3. Barachevsky, V. A.; Strokach, Yu. P.; Puankov, Yu. A.; Krayushkin M. M. J. Phys. Org. Chem. 2007, 20, 1007.

4. Shorunov, S. V.; Krayushkin, M. M.; Stoyanovich, F. M.; Irie, M. Russ. J. Org. Chem. 2006, 42, 1490.

5. Scharf, H.-D.; Korte, F. Chem. Ber. 1965, 98, 764.

6. Khananashvili, L. M.; Andrianov, K. A. Tekhnologiya elementorganicheskikh monomerov $i$ polimerov [Technology of Organoelement Monomers and Polymers], 2nd Edn. Khimiya: Moscow, 1983. 